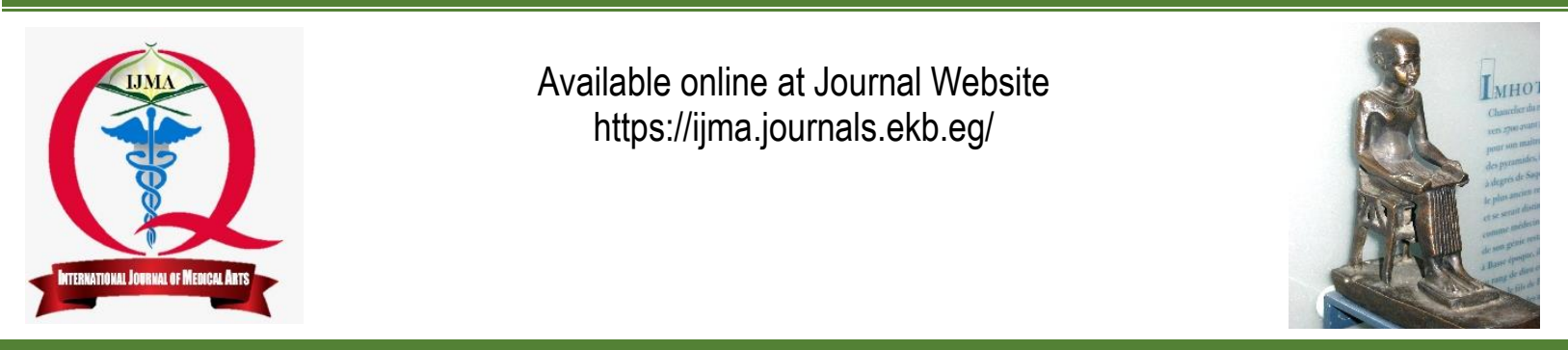

Original article

\title{
Prognostic Factors of Anterior Surgical Approach in Management of Cervical Spondylotic Myelopathy
}

Mohamed Ahmed Ataya, Mohamed Hossam-eldin Aboshahba, Hedaya Hendam, Hatem Mohamed Alsamoly

Department of Neurosurgery, Damietta Faculty of Medicine, Al-Azhar University, Egypt

Corresponding author: Mohamed Ahmed Ataya

Email:drmohamedataya@gmail.com

Received at: December 30, 2019; Revised at: February 1, 2020; Accepted at: February 1, 2020; Available online at: February 1, 2020 DOI: 10.21608/ijma.2020.21664.1067

\section{ABSTRACT}

Background: Spondylotic cervical myelopathy is defined as spinal cord dysfunction secondary to extrinsic compression of the spinal cord and/or its vascular supply so it is the commonest cause of cord dysfunction in patients over 55 years. Main Surgery target is to prevent the progression of symptoms also to improve existing symptoms.

Aim of the work: To determine prognostic factors of patients with spondylotic cervical myelopathy that surgically managed through anterior approach in relation to outcome clinically and radiologically.

Patients and methods: From July 2015 till December 2018, forty patients with cervical myelopathy were operated by anterior surgical approach (anterior cervical discectomy with fusion and/or corpectomy with fusion. Only patients with confirmed spondylotic myelopathy were included; we exclude those with an infectious, inflammatory or neoplastic etiology.

Results: Patients ages were ranged from (40-67) years, with a mean age 53.2 years. Duration of myelopathy ranged from $2-18$ months with a mean duration of 8.55 months. $72.5 \%$ patients were treated by discectomy with fusion and $27.5 \%$ cases were treated by combined discectomy and corpectomy with fusion. Excellent outcome was reported in $22.5 \%$, while $62.5 \%$ cases had good outcome, $15 \%$ patients had fair outcome. Patient age, disease severity, duration, bowel \& bladder manifestations and affection of dorsa column were the prognostic factors in studied patients.

Conclusion: Our study reveals that the significant prognostic factors are: age of patient, severity of myelopathy, duration of myelopathy, presence of bowel or bladder symptoms, dorsal column affection and high signal intensity of T2 weighted MRI.

Keywords: Spondylotic; Myelopathy; Discectomy; Corpectomy; Prognostic factors.

This is an open access article under the Creative Commons license [CC BY] [https://creativecommons.org/licenses/by/2.0/]

Please cite this article as Ataya MA, Aboshahba MH, Hendam H, Alsamoly HM. Prognostic Factors of Anterior Surgical Approach in Management of Cervical Spondylotic Myelopathy. IJMA 2020; 2[1]: 301-307. 


\section{INTRODUCTION}

Spondylotic cervical myelopathy is the commonest cause of spinal cord dysfunction worldwide. The disease is caused by the degeneration of various components of the vertebra, including the vertebral body, the intervertebral disc, the supporting ligaments and the facet joints. There are three important pathophysiologic factors in the development of CSM: static mechanical; dynamic mechanical; and spinal cord ischemia. Long standing cord compression results in irreversible damage including demyelination and necrosis of the gray matter..$^{[1]}$

Patients are presenting with radicular symptoms, a stiff and/or painful neck, paresthesia, gait and balance disturbances, loss of manual dexterity, as well as sphincteric dysfunction. In most of cases there is slow neurological function deterioration. But a stepwise progression of myelopathic symptoms in some cases. ${ }^{[2]}$

Because the spinal cord ventral aspect and nerve roots is mostly compressed, anterior cervical decompression and fusion is an effective and reliable procedure for treatment of cervical spondylotic myelopathy. ${ }^{[3]}$

\section{AIM OF THE WORK}

The present work designed to determine prognostic factors of patients with spondylotic cervical myelopathy that surgically managed through anterior approach in relation to outcome clinically and radiologically

\section{PATIENTS AND METHODS}

This study was carried on 40 patients with spondylotic cervical myelopathy operated by anterior cervical approach to determine the prognostic factors, clinical and radiological outcome. Follow up for the patients clinically and radiologically done immediate postoperative, 6 months and one year postoperative during period from July 2015 to December 2018. Their clinical and radiological data were collected and evaluated. Assessment of motor power is assisted by muscle grading system. All patients were assisted for severity of myelopathy according to grades of Nurick' gait disability scale and functional grading of upper limb adapted from (modified JOA Scale). All patients were subjected to the routine laboratory investigations and radiological investigations including plain x-ray cervical spine A-P and lateral views, MRI cervical spine and CT cervical spine in some cases ossification of posterior longitudinal ligament (OPLL)

Table [1]: Muscle grading system [4]

\begin{tabular}{|c|l|}
\hline Grad & \multicolumn{1}{|c|}{ Ability to move } \\
\hline 0 & Total paralysis \\
\hline 1 & Palpable or visible contraction \\
\hline 2 & Active movement, gravity eliminated \\
\hline 3 & Active movement, against gravity \\
\hline 4 & Active movement, against some resistance \\
\hline 5 & Active movement, against full resistance \\
\hline
\end{tabular}

Table (2): Nurick's gait disability scale[]

\begin{tabular}{|c|l|}
\hline Grade & \\
\hline Grade 0 & Root signs and symptoms - No cord involvement \\
\hline Grade I & Signs of cord involvement - Normal gait \\
\hline Grade II & Mild gait involvement - Able to employed \\
\hline Grade III & Gait abnormality prevents employment \\
\hline Grade IV & Able to ambulate only with assistance \\
\hline Grade V & Chair bound or bed ridden \\
\hline
\end{tabular}

Table (3): The functional grading of the upper limb adapted from the JOA (Modified JOA)[6]

\begin{tabular}{|l|l|}
\hline Grade & \multicolumn{1}{|c|}{ Disability } \\
\hline Grade I & No improvement of finger dexterity for everyday life \\
\hline Grade II & Writing is clumsy but functional, small buttons can be fastened \\
\hline Grade III & Writing is possible but not functional, only large buttons can be fastened \\
\hline Grade IV & Can manage to feed himself \\
\hline Grade V & Unable to feed himself \\
\hline
\end{tabular}


All patients were subjected to anterior cervical approach through anterior cervical discectomy, removal of offending osteophytes and cage fusion or anterior corpectomy with expandable cage fusion if there is ossification of posterior longitudinal ligament. The drill and curette spoons were used for discectomy and corpectomy, removal of osteophytes and decompression of the nerve roots. In cases, with suspicion of instability anterior plate and screws were applied. Postoperative clinical state is assessed according to the criteria of improvement of Nurick and modified JOA scales. Postoperative radiological evaluation includes immediate postoperative $\mathrm{x}$-ray cervical spine AP and lateral views to assess alignment of cervical spine immediate postoperative, at 6 and 12 months postoperatively to assessed fusion rate and remote complications.

Outcome: The overall outcome of was assisted by the clinical grading outcome scale.

Data analysis: collected data analyzed by the aid of statistical package for social science (SPSS) version 20 (IBM, SPSS, Inc., Chicago, USA). Frequency and percent were calculated for qualitative variables, while mean and standard deviation (SD) were calculated for numerical variables. Chi square test and one-way analysis of variance were used for comparison between categorical and numerical variables. $P$ value $<0.05$ was considered significant.

Table (4): Clinical grading of outcome scale[]]

\begin{tabular}{|l|l|}
\hline \multicolumn{1}{|c|}{ Grade } & \multicolumn{1}{c|}{ Outcome } \\
\hline Excellent & All preoperative symptoms relived; abnormal finding improved. \\
\hline Good & Minimal persistence of preoperative symptoms, abnormal finding unchanged or improved. \\
\hline Fair & Definite relive of some preoperative symptoms, other symptoms and abnormal finding unchanged. \\
\hline As pre-op. & No change of clinical state. \\
\hline Poor & Preoperative symptoms and signs became worse postoperative. \\
\hline
\end{tabular}

\section{RESULTS}

The age of patients was ranged from (40-67) years, with a mean age 53.2 years. The median age was 54 years. Age groups between (40-49) years were $12(30 \%)$ patients, age groups between (50 $59)$ years were $22(55 \%)$ patients and age groups between $(60-69)$ years were $6(15 \%)$ patients. There were $33(82.5 \%)$ males and $7(17.5 \%)$ were females.

Symptoms include lower limb weakness in 40 $(100 \%)$ patients, clumsy hand in $39(97.5 \%)$, abnormal gait in $38(95 \%)$, paresthesia in upper extremities in $32(80 \%)$, Neck pain in $28(70 \%)$, radicular pain in $15(37.5 \%)$, bowel or bladder symptoms in 19(47.5\%) patients. Signs include, spastic mono, para or quadriparesis were in 40 $(100 \%)$ patients, exaggerated jerk reflexes in 40 $(100 \%)$, clonus in $38(95 \%)$, extensor plantar response in $33(82.5 \%)$, equivocal planter response in $7(17.5 \%)$, Hoffman's sign in $23(57.5 \%)$, hyperactive pectoralis reflex in 18 (45\%), L'hermitte sign in $17(42.5 \%)$, inverted radial reflex in 13 $(32.5 \%)$ and dorsal column affection in $9(22.5 \%)$. The duration of myelopathy ranged from 2 to 18 months. The mean duration was 8.55 months and the median duration was 9 months.

Severity of myelopathy assessment by The functional grading of modified JOA scale was compared with pre-and postoperative as follow; preoperative, there was one $(2.5 \%)$ patient had grade I, $14(35.0 \%)$ had grade III, $23(57.5 \%)$ had grade IV, and $2(5 \%)$ had grade V. Postoperative, there were $9(22.5 \%)$ patients having grade I, 25 $(62.5 \%)$ having grade II, and $6(15 \%)$ having grade III. The mean functional grading of JOA scale was improved from 3.65 preoperative to 1.93 postoperative. Nurick's gait disability scale was compared with pre-and postoperative as follow; preoperative Nurick's gait disability grade III, there were 21 patients, $12(57.1 \%)$ had improved to grade I, and 7 (33.3\%) had improved to grade II, and 2 $(9.5 \%)$ were remain grade III.

In preoperative Nurick's gait disability grade IV, there were 16 patients, one patient $(6.2 \%)$ had improved to grade I, and $12(75 \%)$ had improved to grade II and 3 patients (18.8\%) were recovered to grade III. In preoperative Nurick's gait disability 
Ataya MA, et al.

grade V, there were 3 patients, all patients (100\%) were recovered to grade II. The mean Nurick's grade was improved from 3.55 preoperatively to 1.80 at the latest follow up. High signal intensity on T2 weighted MRI sagittal view was positive in 29 $(72.5 \%)$ patients and was negative in $11(27.5 \%)$ patients.
Regarding number of levels of compression, one level of compression was in $3(7.5 \%)$ patients, two levels of compression were in $28(70 \%), 3$ levels of compression were in $8(20 \%)$ and 4 levels of compression were in one $(2.5 \%)$ patient.

Table (5): Relation between each of age and duration of myelopathy with outcome among studied group

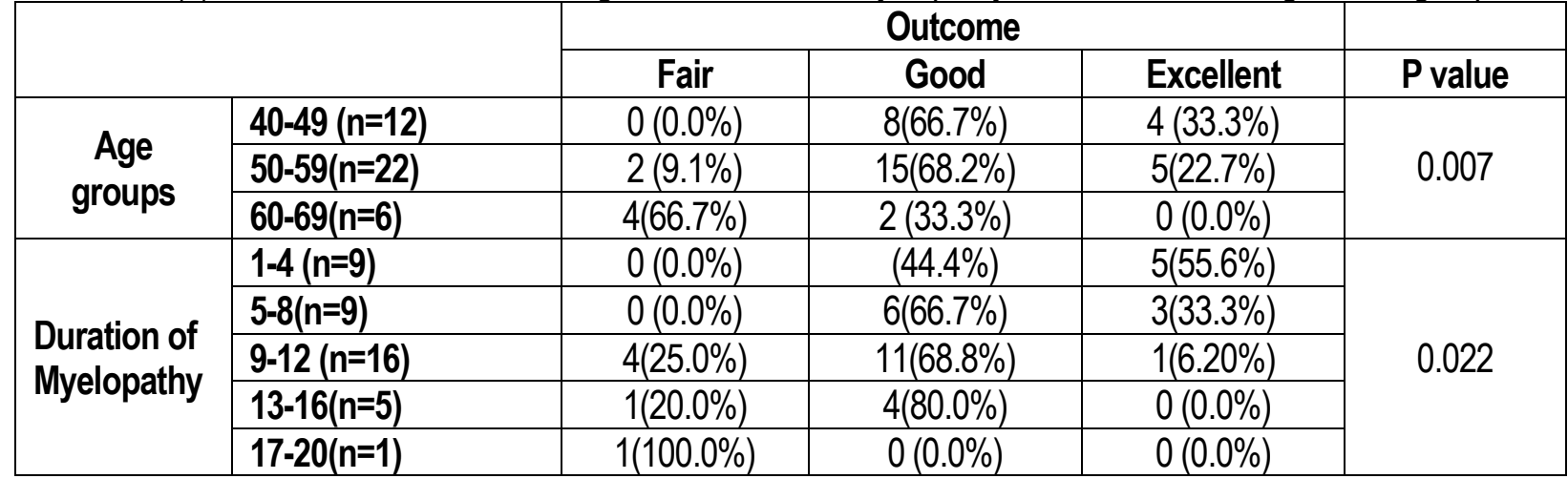

Table (6): Relation between dorsal column affection, preoperative functional grading of modified JOA scale, and High signal intensity on T2 weighted MRI sagittal view with outcome among studied group.

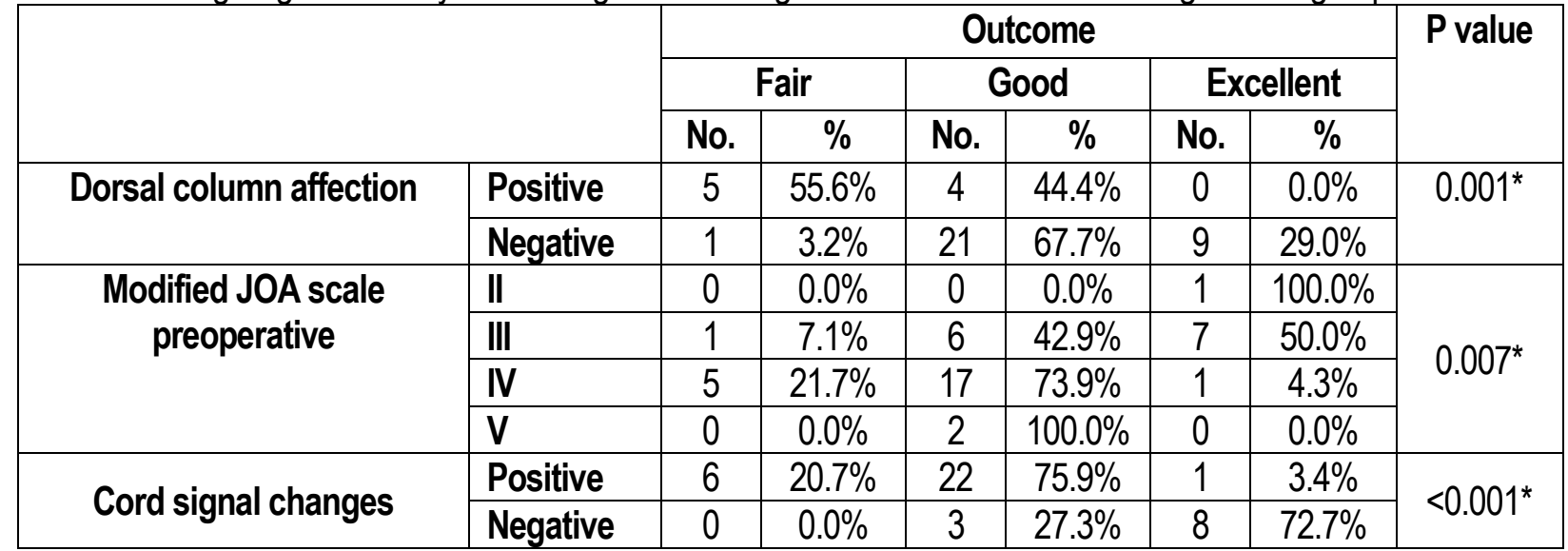

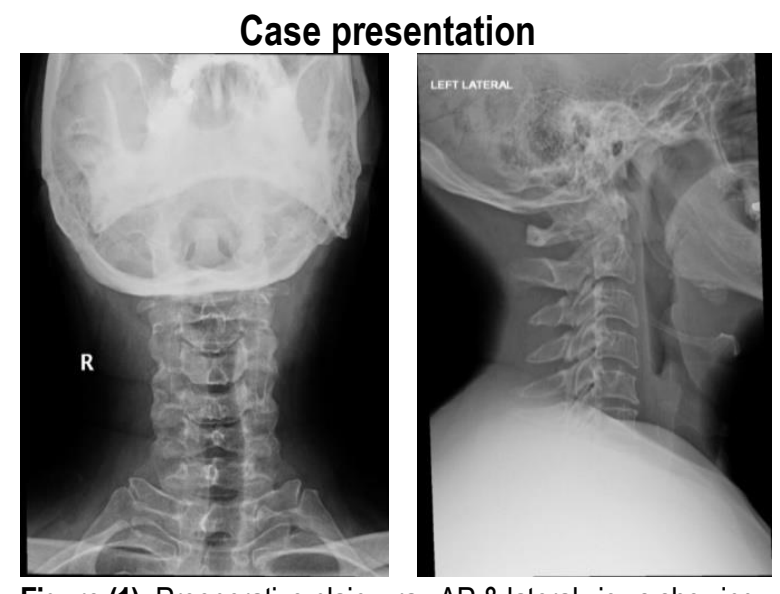

Figure (1): Preoperative plain $x$ ray AP \& lateral views showing straightened cervical curve, narrow disc space at C5/6 \& C6/7.

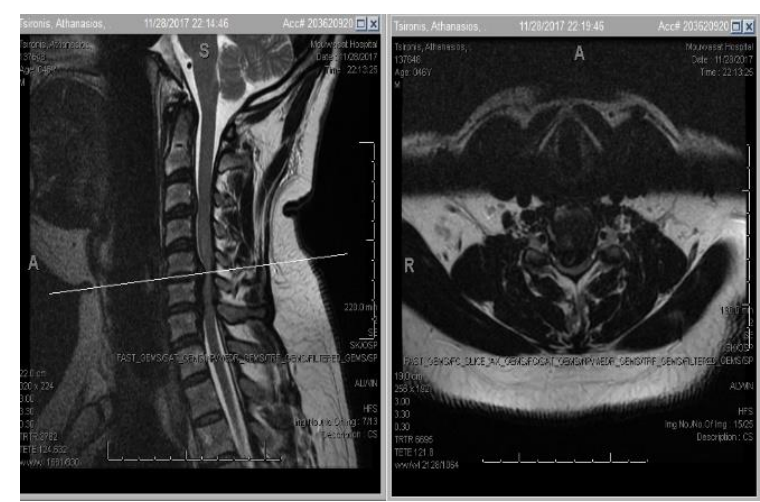

Figure (2): Preoperative T2 weighted MR image sagittal and axial views showing degenerative disc lesions and cord compression at the level of C5/6 \&C6/7 with high signal intensity opposite C5/6 level. 


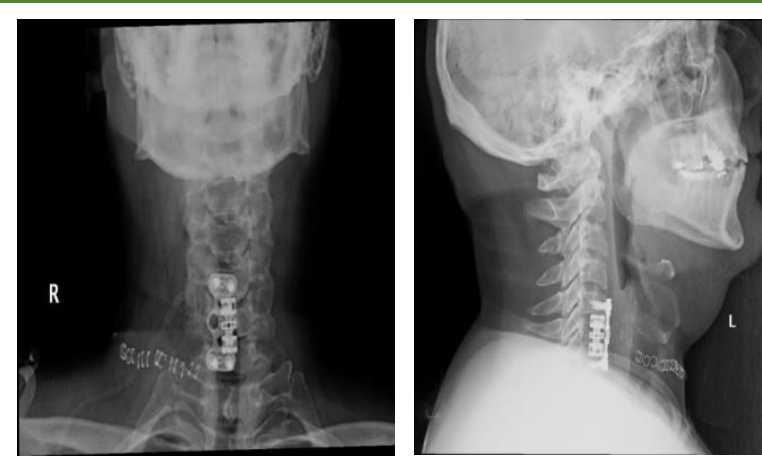

Figure (3): Immediate Postoperative x ray cervical spine AP \& lateral views showing good graft position and stable plate fixation
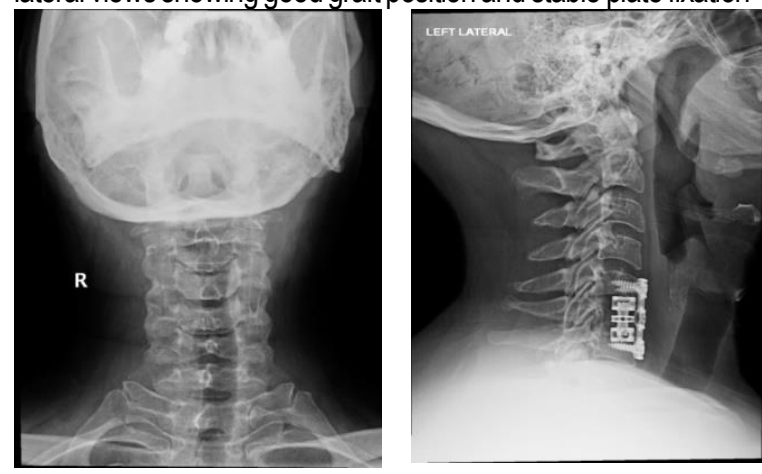

Figure (4): Follow up x ray cervical spine AP \& lateral views showing good graft position and stable plate fixation

\section{DISCUSSION}

It is generally accepted that a combination of compressive factors, both anatomical and dynamic, as well as vascular phenomena are responsible for the clinical syndrome. ${ }^{[8]}$

The principal neuropathological features are cystic cavitation, gliosis and degeneration, Wallerian degeneration of posterior columns, and posterolateral tracts and anterior horn cell loss at the site of compression. ${ }^{[9]}$

Surgery is superior to conservative measures. It is recommended for patients who have either substantial or progressive impairment of neurologic function without sustained remission. ${ }^{[10]}$

The goal of surgical treatment is to relieve the compression on the cord while maintaining spinal stability. [11]

In this series the age group between $40-49$ years, there were 12 patients $(30 \%)$, 8 patients $(66.7 \%)$ have good outcome, 4 patients $(33.3 \%)$ have excellent outcome. In the age group between 50-59 years, there were 22 patients (55\%), 2 patients $(9.1 \%)$ have fair outcome, 15 patients $(68.2 \%)$ have good outcome, 5 patients $(22.7 \%)$ have excellent outcome. In the age group between 60-69 years, there were 6 patients (15\%), 4 patients $(66.7 \%)$ have fair outcome, 2 patients $(33.3 \%)$ have good outcome. These differences between age distribution and outcome are statistically significant $(P=0.007)$.in other series, no relationship was noted between prognosis and age. Age was not predictive of outcome in CSM[12].

Age at surgery was not so accurate in predicting surgical outcome. ${ }^{[13]}$ Better results were observed in younger patients of CSM ${ }^{[14]}$ according to yamazaki et al, the degree of recovery is expected to be smaller than in elderly patients than in younger patients ${ }^{[15]}$

In this series, duration of myelopathy ranged from 2 to 18 months. The mean duration was 8.55 months. The median duration was 9 months. In other series, the average duration of preoperative symptoms was less than one year in 40 patients, between 1-3 years in 28 patients, and more than 3 years in 16 patients [7]. All patients had been symptomatic for less than 1 year. ${ }^{[16]}$

In this series the duration of myelopathy between 1-4 m, there were 9 patients. 5 patients $(55.6 \%)$ had an excellent outcome and 4 patients $(44.4 \%)$ had good outcome. duration between 4-8 $\mathrm{m}$, there were 9 patients. 3 patients $(33.3 \%)$ had an excellent outcome and 6 patients $(66.7 \%)$ had good outcome. duration between 8-12 m, there were 16 patients. 1 patient $(6.2 \%)$ had an excellent outcome \& 11 patients $(68.8 \%)$ had good outcome and 4 patients $(25.0 \%)$ had fair outcome. duration between $12-16 \mathrm{~m}$, there were 5 patients. 4 patients $(80.0 \%)$ had good outcome and 1 patient $(20.0 \%)$ had fair outcome. duration between $16-20 \mathrm{~m}$, there was 1 patient. The patient had fair outcome. These differences between duration groups and outcome are statistically significant $(P=0.022)$. In series of Ebersold et al, the symptoms duration is very important as an indicator of excellent recovery in elderly patients. Duration of symptoms was of prognostic significance in cervical myelopathy[8] Multiple regression analysis revealed that the most significant prognostic factor was the transverse area of the spinal cord, followed by the duration of symptoms [13]

Bowel or bladder symptoms represented a late 
symptom. There were 19 patients having positive bowel or bladder symptoms. 14 patients (73.7\%) had good outcome, and 5 patients $(26.3 \%)$ had fair outcome. These differences are statistically significant $(P=0.001)$. There were 7 patients having +ve bladder symptoms preoperatively, 5(71.5\%) patients had good outcome and 2(28.5\%) had poor outcome with $p$ value $=0.062$. Dorsal column affection, there were 9 patients had late signs of dorsal column affection, 5 of them (55.6\%) had fair outcome while 4 of them (44.4\%) had good outcome. These differences are statistically significant $(P=0.001)$ and these results agree with results of Cheung et al series [17] mentioned that the neurological recovery apparently was worst in cases with sphincteric dysfunction

In this series, the functional grading modified JOA scale were compared with pre-and postoperative as follow, in preoperative grade II, there was 1 patient (100\%) that improved to grade I. In preoperative grade III, there were 14 patients. 7 patients (50\%) improved to grade I, 6 patients (42.9\%) improved to grade II and 1 patient (7.1\%) improved to grade III. In preoperative grade IV, there were 23 patients. 1 patient (4.3\%) improved to grade I, 17 patients $(73.9 \%)$ improve to grade II, and 5 patients $(21.7 \%)$ improved to grade III. In preoperative grade $\mathrm{V}$, there were 2 patients. The 2 patients improved to grade II. The average functional grading of the upper limb adapted from JOA improved from 3.65 preoperative to 1.93 at the latest follow up. These differences were highly statistically significant ( $P$ value: 0.001$)$. the functional grading JOA scale were compared with the outcome as follow, in preoperative grade II, there was1 patient $(100 \%)$ that had an excellent outcome. In preoperative grade III, there were 14 patients. 7 patients (50\%) had an excellent outcome and 6 patients $(42.9 \%)$ had good outcome and 1 patient $(7.1 \%)$ had fair outcome. In preoperative grade IV, there were 23 patients. 1 patient (4.3\%) had an excellent outcome, 17 patients $(73.9 \%)$ had good outcome, and 5 patients $(21.7 \%)$ had fair outcome. In preoperative grade $\mathrm{V}$, there were 2 patients. The 2 patients (100\%) had good outcome. These differences were highly statistically significant. ( $P$ value: 0.007 ) and is strongly correlated to surgical outcome.
Preoperative JOA grade IV\&V had the most statistically significant correlation with poor outcome with $77 \%$ (24 out of 31 ) while $100 \%$ (7 out of 7) patients with preoperative JOA grade I \& II had good recovery. Our study coincides with study of Aggrawal et al.[18]

In this series, 29 patients had positive high signal intensity on T2 weighted MRI sagittal view. One patient (3.4\%) had an excellent outcome, 22 patients $(75.9 \%)$ had good outcome, and 6 patients $(20.7 \%)$ had fair outcome. 11patients had negative high signal intensity on T2 weighted MRI sagittal view. 8 patients $(72.7 \%)$ had excellent outcome and 3 patients $(27.3 \%)$ had good outcome. These differences were statistically close to be significant ( $P$ value $<0.001$ ). Our study was coinciding with a study of Matsuda et al.[19]. In contrast to series; they found that the presence or absence of a high intensity area was not correlated with the severity of symptoms or the surgical outcome[20]

Conclusion: Our statistical analysis revealed that the significant prognostic factors of outcome of cervical spondylotic myelopathy were: age of the patient, duration of myelopathy before surgery, severity of myelopathy, presence of bowel or bladder symptoms, dorsal cord affection and presence of high signal intensity of T2 weighted MRI sagittal view. The corner stone for excellent and good outcome of cervical spondylotic myelopathy is early diagnosis as this will lead to low grade myelopathy, absence of cord changes and short duration of symptoms

\section{Financial and Conflict of interest disclosure}

Authors declare that there was no conflict of interest.

\section{REFERENCES}

1. Tetreault LA, Karpova A, Fehlings MG. Predictors of outcome in patients with degenerative cervical spondylotic myelopathy undergoing surgical treatment: results of a systematic review. Eur Spine J 2015; 24 (Suppl 2), 236-251. [DOI10.1007/s00586-013-2658-z].

2. Pumberger $M$, Froemel $D$, Aichmair $A$, Hughes AP, Sama A, Cammisa FP, Girardi FP. Clinical predictors of surgical outcome in cervical spondylotic myelopathy: an analysis of 248 
patients. Bone Joint J. 2013; 95-B: 966-71. [DOI: 10.1302/0301-620X.95B7.31363].

3. Reitman CA, Hipp JA, Nguyen L, Esses SI. Changes in segmental intervertebral motion adjacent to cervical arthrodesis: a prospective study. Spine (Phila Pa 1976) 2004; 29(11): E221E226. [DOI: 10.1302/0301-620X.95B7.31363].

4. Rieger A, Holz C, Marx T, Sanchin L, Menzel M. Vertebral autograft used as bone transplant for anterior cervical corpectomy: technical note. Neurosurgery 2003;52: 449-454. [DOI: 10.1227/ 01. NEU.0000043815.31251.5B]

5. Clark CR. Cervical spondylotic myelopathy: History and physical findings. Spine.1988; 13: 847 - 849. [DOI:10.1097/00007632-198807000-000 26].

6. Tani T, Ishida K, Ushida T, Yamamato H. Intraopertive electroneurography in the assessment of the level of operation for cervical spondylotic myelopathy in the elderly. J Bone Joint Surg Br. 2000;82(2):269-74. [DOI: 10.1302/0301-620X. 82B2. 0820269].

7. Brodsky AE, Khalil MA, Sassard WR, Newman BP. Repair of symptomatic pseudarthrosis of anterior cervical fusion: posterior versus anterior repair. Spine 1992; 17:1137-1143. [DOI: 10.1097/ 00007632-199210000-00002].

8. Ebersold MJ, Pare MC, Quast LM. Surgical treatment for cervical spondylotic myelopathy. J Neurosurgery.1995; 82: 745 -751. [DOI: 10.3171/ jns.1995.82.5.0745].

9. Sekhon LHS. Cervical arthroplasty in the management of spondylotic myelopathy. J Spinal Dis Tech. 2003; 16: 307 - 313. [DOI: 10.1097/ 00024720 -200308000-00001].

10. Martin-Benlloch JA, Maruenda-Paulino Jl, Barra-Pla A, Laguia-Garzaran M. Expansive laminoplasty as a method for managing cervical multilevel spondylotic myelopathy. Spine 2003; 28 : 680-684. [DOI: 10.1097/01.BRS. 0000051913. 55259.5F].

11. Orr RD, Zdeblick TA. Cervical spondylotic myelopathy: approach to surgical treatment. Clin Orthop Relat Res. 1999; (359): 58-66. [PMID: 10078129].

12. McCormick WE, Steinmetz MP, Benzel EC. Cervical spondylotic myelopathy: make the difficult diagnosis, then refer for surgery. Cleve Clin J Med. 2003; 70(10):899-904. [DOI:10.3949/ccjm.70. 10. 899]
13. Wada E, Yonenobu K, Suzuki S, Kanazawa A, Ochi T. Can intramedullary signal change on magnetic resonance imaging predict surgical outcome in cervical spondylotic myelopathy. Spine (Phila Pa 1976). 1999 Mar 1;24(5):455-61 [DOI: 10.1097/ 00007632-199903010-00009].

14. George B, Gauthier N, Lot G: Multisegmental cervical spondylotic myelopathy and radiculopathy treated by multilevel oblique corpectomies without fusion. Neurosurgery. 1999;44(1):81-90. [DOl: 10.1097/ 00006123-199901000-00046].

15. Yamazaki T, Yanaka K, Sato H, Uemura K, Tsukada A, Nose T. Cervical spondylotic myelopathy: surgical results and factors affecting outcome with special reference to age differences. Neurosurgery. 2003; 52: 122 - 126. [DOI: 10.10971 00006123-200301000-00015].

16. Saunders RL, Pikus HJ, Ball P. Four level cervical corpectomy Spine (Phila Pa 1976). 1998; 23 (22):2455-61. [DOI: 10.1097/00007632-1998 11150-00022].

17. Cheung W, Arvinte D, Wong Y, Luk K, Cheung K. Neurologic recovery after surgical decompression in patients with cervical spondylotic myelopathy-a prospective study. Int Orthop. 2008; 32 (2): 273-8. [DOI: 10.1007/s00264-0060315-4].

18. Aggarwal RA, Srivastava SK, Bhosale SK, Nemade PS. Prediction of surgical outcome in compressive cervical myelopathy: A novel clinicradiological prognostic score. J Craniovertebr Junction Spine. 2016;(2):82-6. [DOI: 10.4103/ 0974- 8237.181828].

19. Mastuda Y, Miyazaki K, Tada K, Yasuda A, Nakayama T, Murakami H, Matsuo M. Increased MR signal intensity due to cervical myelopathy. J Neurosurg. 1991 Jun;74(6):887-92. [DOI: 10.3171/ jns.1991.74.6.0887].

20. Yone K, Sakou T, Mitsuhiro Y, ljiri K. Preoperative and postoperative magnetic resonance image evaluations of the spinal cord in cervical myelopathy. Spine (Phila Pa 1976). 1992; 17(10 Suppl): S388-92. [DOI: 10.1097/ 00007632199210001-00008]. 